\title{
Case of Acute Ataxia and behavioral disturbances as the only Signs of Abdominal Neuroblastoma
}

\author{
F. Jaafari ${ }^{1 *}$, B. Bannar ${ }^{1}$, I. Zouita ${ }^{1}$, D. Basraoui ${ }^{1}$, H. Jalal ${ }^{1}$
}

${ }^{1}$ Radiology Department, Mother and children Hospital, CHU Mohammed VI, Cadi Ayad University, Marrakech, Morocco

DOI: $10.36347 /$ sjmcr.2021.v09i03.014

| Received: 17.02.2021 | Accepted: 11.03.2021 | Published: 15.03.2021

*Corresponding author: Fadwa Jaafari

\section{Abstract}

Childhood presentations of ataxia, an impairment of balance and coordination caused by damage to or dysfunction of the cerebellum, can often be challenging to diagnose. Ataxia alone is rare as a paraneoplastic sign, especially if it is due to neuroblastoma (abdominal or chest). Although the pathogenesis is not known, the association of these entities shows similarity to the adult association of cerebellar ataxia with occult neoplasms. Chest and abdominal imaging may aid in diagnosing otherwise silent and occult neuroblastoma and is recommended when cerebellar ataxia is present. We report an abdominal neuroblastoma in a one and half year-old boy presenting with only acute ataxia, behavioral disturbances and abnormal neuroimaging. Brain MRI showed abnormal signal finding in the occipital subcortical white matter and the periventricular space. In the abdominal CT, a mass was detected in the left adrenal gland. We suggest in children with acute ataxia, with or without opsoclonus-myoclonus, neuroblastoma should be considered.

Keywords: Neuroblastoma, Abnormal Neuroimaging Finding, Acute Ataxia, MRI.

Copyright ( 2021 The Author(s): This is an open-access article distributed under the terms of the Creative Commons Attribution 4.0 International License (CC BY-NC 4.0) which permits unrestricted use, distribution, and reproduction in any medium for non-commercial use provided the original author and source are credited.

\section{INTRODUCTION}

Neuroblastoma is a common childhood tumor that arises from sympathetic nerve cells; $2 \%$ to $3 \%$ of children with neuroblastoma have development of opsoclonus-myoclonus-ataxia (OMA) syndrome, an acute neurologic disorder characterized by involuntary, chaotic eye movements, myoclonic limb jerking, and ataxia $[1,2]$. It is important to exclude OMS, even when neither opsoclonus nor myoclonus is present; consequently, acute ataxia, as the only sign should be considered [3]. OMS particularly originates from the middle part of the cerebellum and single photon emission computed tomography (SPECT) is the best way to detect functional deterioration in these patients [3]. The exact mechanism of neurologic damage in OMA remains undetermined. A proposed autoimmune cause is supported by detection of antineuronal immunoactivity in sera of affected patients, as well as response of OMA symptoms to immunosuppressive therapies [4-7]. In OMS patients, immunologic abnormalities including T-cell abnormalities, decrease of CD4+, T-cell subset and the CD4/CD8 ratio have been detected [8]. Initially, the syndrome was attributed either to the presence of occult neuroblastoma or to an unknown cause. With improved imaging techniques, approximately all cases appear to be related to neuroblastoma [9].

\section{Case Presentation}

A One and half-year-old boy was refered to our radiology department with acute ataxia and behavioral disturbances for brain MRI, he had this complaint from 2 weeks ago, and there was no history of previous infections, drug ingestion, trauma, seizure, vomiting or positive family history of ataxia. Neurodevelopmental milestones were adequate. Physical examination of the chest, abdomen and musculoskeletal system were normal. Neurological examination revealed intact cranial nerves, truncal and limb ataxia and dysarthria. Nystagmus, opsoclonus and myoclonus were negative and the mental status was normal. Routine laboratory tests were normal. Brain MRI showed several hyperintensities T2 in the in the occipital subcortical white matter and the periventricular space (Fig-1). Based on the above mentioned findings, at first our impression was ADEM (Acute Disseminated Encephalo Myelitis), but to rule out other possibilities, abdominal and chest CT were performed. Chest CT was normal but in the abdominal $\mathrm{CT}$, there was a mass in the left adrenal gland crossing the midline (Fig-2). Neuroblastoma was the first diagnosis, which wasconfirmed by histopathological examination, We suggest in children with acute ataxia, with or without opsoclonus-myoclonus, neuroblastoma should be considered. 


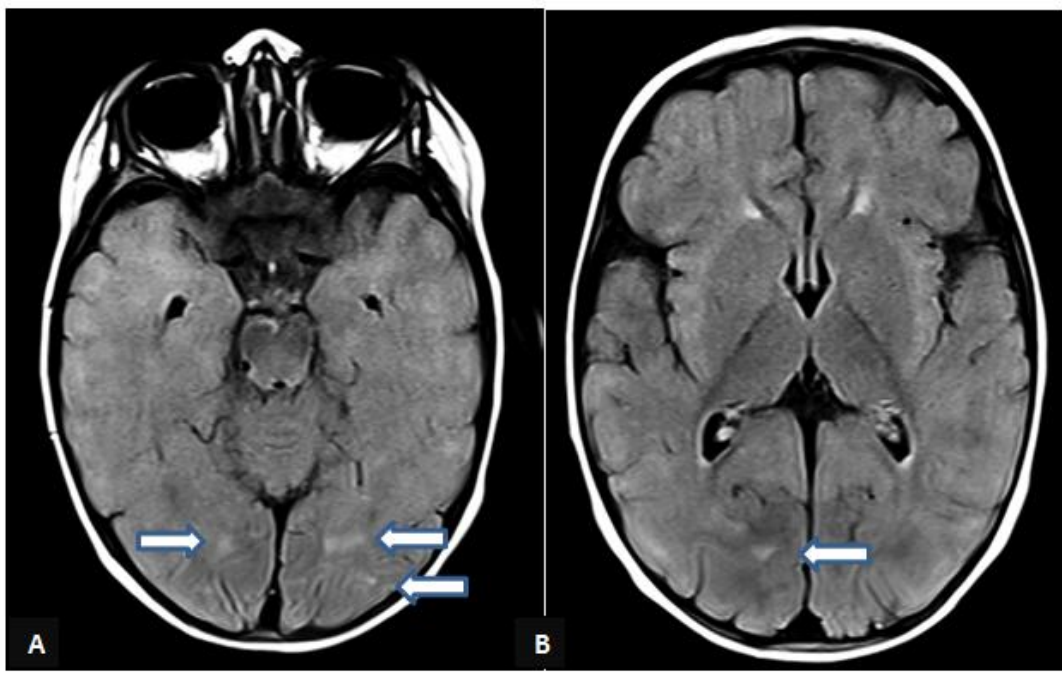

Fig-1: A and B, A One and half -year-old girl with abdominal neuroblastoma. Two sections of axial T2- FAIR Weighted images showing hyper intensity in the bilateral occipital subcortical white matter and the periventricular space

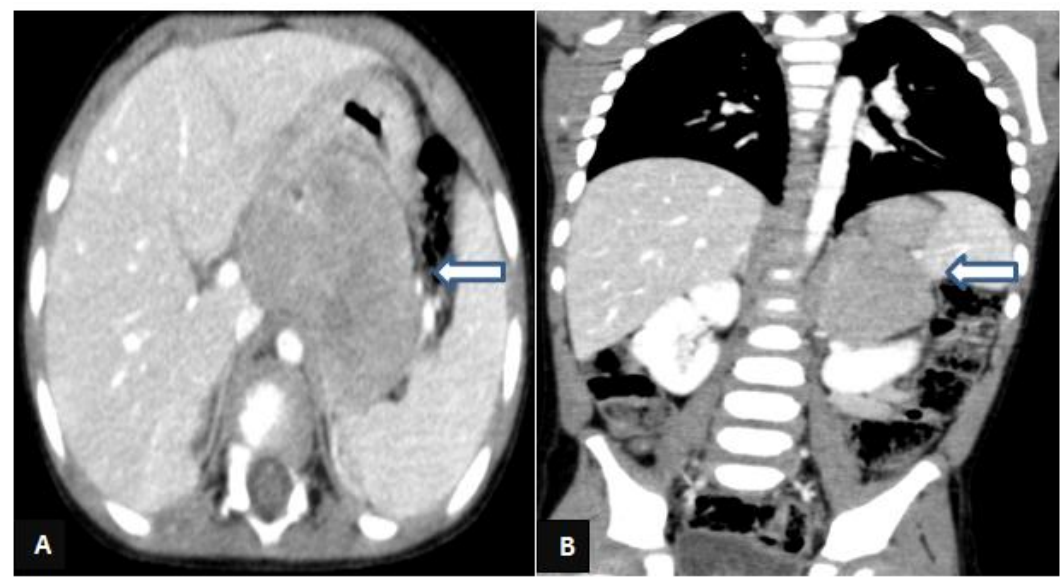

Fig-2: Axial (A) and coronal (B) abdominal CT scan with contrast revealing soft tissue mass over the left kidney in the region of the left adrenal gland corresponding to a neuroblastoma

\section{DISCUSSION}

Acute ataxia has many etiologies. ADEM and Kinsbourne syndrome are two rare causes of acute ataxia. Abnormal neuroimaging is usual in ADEM, but rare in Kinsbourne syndrome [10]. Although an occasional case of neuroblastoma in association with acute cer ebellar ataxia had been rep orted in the literature, Solomon and Chutorian [11] were the first to emphasize this interesting coincidence in 1968. Because of the rep orted association, an intravenous urogram was obt ained in the patient de scribed above. The examination led to the diagnosis and treatment of an otherwise occult and silent neuroblastoma. The acute cer ebellar syndrome, as seen in our patient, has been referred to as op soclonus, ataxic conjugate movements of the eyes, acute cerebellar ataxia, and mild clonic encephalopathy of infants [12]. In addition to ataxic movemen $t$ of the trunk, head, and extre mities, a peuliar rapid flutter ing movement of the eyes was present in most of the patients and has been called opsoclonus. The syndrome was also frequently associated with some degre e of mental retardati on or dementia. Some studies reported an association between OMS (without neuroblastoma) and focal lesions in the brain stem (especially pontine lesions) in MRI. In the review of literature, two patients with OMS whose MRIs showed brain stem lesions and developed OMS after an upper respiratory tract illness were reported. In one case, the lesion was in the pons at the junction of basis and tegmentum and in another case, a focal lesion was located in the upper pontine tegmentum[13]. The neurologic disease was relatively self-limite d, and most of the patients improved slowly but defini tely in the months after di agnosis and treatment [12]. A complete return to normal was noted in some. The exact pathologic lesion has not been identified, but a similar association of cerebellar ataxia with occult neoplasms in adults $\mathrm{h}$ as been accompanied with diffuse loss of Purkinj e's cells and minimal abnormalities of the dentate nucleus, without any metastatic' lesion in the central nervous system [14]. The prognosis of neuroblastoma is moderately favorable when the tumor is treated intensively at an early age [15]. This favorable outlook may $r$ elate to the relatively high rate of spontaneous re gression of the tumor [16]. Since the 
F. Jaafari et al., Sch J Med Case Rep, Mar, 2021; 9(3): 246-248

progno is is better in childr en under two years of age, diagnosis in the "silent" stage would appear to be a desirable goal. Of importance in our case was the radiologic diagnosis of an asymptomatic nonpalpable neu roblastoma. The interrelationship between neuroblastoma and acute cerebellar ataxia is obscure but Bray et al., [12] postulate that: (a) an undefined agent may induce both carcinogenes is and encephalopathy; (b) an occult neuroblas toma may cause an antigen-antibody reaction within the cerebellum; or (c) toxic cerebellar damage may be produced by the neu roblastoma. In our case, the pontine tegmentum was intact and absence of opsoclonus-myoclonus was described with the location of the lesion. Therefore, our patient is the first case of neuroblastoma and its paraneoplastic syndrome, manifesting only with acute ataxia and abnormal neuroimaging finding in the occipital subcortical white matter and the periventricular space. Despite the lack of pathogenetic understanding the radiologist should be familiar with this newly recognized association and should recommend a chest and abdominal imaging in any child with acute cerebellar ataxia.

\section{REFERENCES}

1. Solomon GE, Chutorian AM. Opsoclonus and occult neuroblastoma. N Engl J Med. 1968;279:475-7.

2. Matthay K. Neuroblastoma: a clinical challenge and biologic puzzle. Cancer J Clin. 1995;24:17992.

3. Oguro K, Kobayashi J, Aiba H, Hojo H. Opsoclonus-myoclonus syndrome with abnormal single photon emission computed tomography imaging. Pediatr Neurol. 1997 May:16(4):334-6.

4. Telander RL, Smithson WA, Groover RV. Clinical outcome in children with acute cerebellar encephalopathy and neuroblastoma. J Pediatr Surg. 1989; 24:11-4.

5. Connolly AM, Pestronk A, Mehta S, Pranzatelli MR III, Noetzel MJ. Serum autoantibodies in childhood opsoclonusmyoclonus syndrome: an analysis of antigenic targets in neural tissues. J Pediatr. 1997; 130:878-84.

6. Fisher PG, Wechsler DS, Singer HS. Anti-Hu antibody in a neuroblastoma associated paraneoplastic syndrome. Pediatr Neurol. 1994;10:309-12.

7. Antunes NL, Khakoo Y, Matthay KK, Seeger RC, Stram DO, Gerstner E, Abrey LE, Dalmau J. Antineuronal antibodies in patients with neuroblastoma and paraneoplastic opsoclonusmyoclonus. Journal of pediatric hematology/oncology. 2000 Jul 1;22(4):315-20.

8. Menkes JH. Childhood neurology. 7th ed. Williams \& Wilkins: Philadelphia: 2006. p. 592-4.

9. Fenichel JM. Clinical pediatric neurology. 5th ed. Philadelphia: Elsevier/ Saunders: 2005. p. 226.

10. Molla Mohammadi M, Karimzadeh P, Khatami A, Jadali F. IRM cérébrale anormale dans un cas d'ataxie aiguë comme seul signe de neuroblastome abdominal. Journal iranien de radiologie, 2010; 7(3):167-169.

11. Solomon GE, Chutorian AM. Opsoclonus and occult neuroblastoma. New Eng J Med. 196829 Aug; 279:475-477.

12. Bray PF, Ziter FA, Lahey ME, Myers GG. The coincidence of neuroblastoma and acute cerebellar encephalopathy. The Journal of pediatrics. 1969 Dec 1;75(6):983-90.

13. Hattori $\mathrm{T}$, Hirayama $\mathrm{K}$, Imai $\mathrm{T}$, Yamada $\mathrm{T}$, Kojima S. Pontine lesion in opsoclonusmyoclonus syndrome shown by MRI. J Neurol Neurosurg Psychiatr. 1988;51(12):1572-5.

14. Brain WR, Wilkinson M. Subacute cerebellar degenerat ion in patients wit h carcinoma. [In] The Remote Effects of Cancer Oil the Nervous System. New York, Grune and Stratton. 1965; 1:17-23.

15. Lingley JF, Sagerman RH, Santulli TV, Wolff JA. Neuroblastoma: Management and survival. New England Journal of Medicine. 1967 Dec 7;277(23):1227-30.

16. Bill AH Jr. The regression of neuroblastoma. J Pediat Surg. 1968 Feb; 3:103-106. 